\title{
Aganwadi Community Health Workers: Awareness, Knowledge, Attitude and Beliefs about Diabetes Mellitus and Its Effect on Oral Health in Nagpur District
}

Surekha Rathod ${ }^{1}$ and Grishmi Niswade ${ }^{2 *}$

${ }^{1}$ Department of Periodontology, VSPM Dental College and Research Centre, Nagpur, Maharashtra, India

${ }^{2}$ Department of Periodontology, Swargiya Dadasaheb Kalmegh Smruti Dental College and Hospital, Nagpur, Maharashtra, India

\begin{abstract}
Purpose: This study aimed to evaluate the oral health related awareness and practicesof diabetes mellitus and its effects on oral health in anganwadi workers.

Study design: It is an interventional type of study.

Materials and methods: 200 anganwadi workers from the areas of Hingna, Wanadongri, Gumgaon and Wadhdhamna in Nagpur district and 30 interns participated in the study. In the first part, all the interns were trained for a module that contained what are diabetes, aetiology, signs and symptoms of diabetes, complications, management and prevention of diabetes mellitus in Marathi language. In second part to know the awareness of diabetes, a pre-test was conducted and a validated questionnaire was distributed to the participant. Following this the interns educated the Aganwadi workers regarding diabetes through this module for 30 minutes and also information leaflets were distributed to the participants. In third part post -test was conducted for the participant. Descriptive statistics were used to report the results of the study.
\end{abstract}

Results: The knowledge of the participants was assessed using 16 questions related to diagnosis, risk factors, prevention and complications of diabetes and its relationship with oral health. Out of the total 100 participants, the pre-test showed an average of 36 participants to be aware about diabetes and the post test showed an average of 77 participants to have improved their knowledge.

Conclusion: Awareness and education programs should be planned and conducted for anganwadi workers according to community needs.

Keywords: Anganwadi workers; Diabetes; Education; Awareness

\section{Introduction}

Diabetes is a diverse group of metabolic disorders that is characterised by soaring levels of glucose in blood. These elevated levels of glucose are a result of paucity of insulin secretion caused by pancreatic $\beta$ - cell dysfunction or by resistance to the action of insulin or a blend of these [1]. The disease is characterised by abnormalities in carbohydrate, fat and protein metabolism and results in chronic complications including microvascular, macrovascular and neuropathic disorders [2]. The oral complications include gingivitis, periodontitis, xerostomia, delayed wound healing, opportunistic infections, candidiasis, altered taste sensation etc [3,4]. Diabetes has a dramatic impact on the general health of the patient causing a high degree of mortality and morbidity placing a monetary burden on the health care system. The International Diabetes Federation has stated that the 78 million people in the South East Asia region suffer from diabetes and this number will rise to 140 million up to the year 2040 [5]. The prime objective of management of diabetes mellitus is to adjourn the macro and microvascular complications by achieving optimal glycaemic control [6]. The management protocol involves medications, lifestyle modifications including consistent exercise, healthy diet and nutrition and weight loss. To follow this protocol for treating the disease, health literateness is important. It has been observed that patients, who have a good knowledge about diabetes and its complications, seek proper treatment and care, take charge of their health and achieve better glycaemic control [7].

Aganwadi workers are a bridge between the rural population and doctors and are front line community health workers assigned to work for identifying diseases in the community and creating awareness in the public about the treatment of the same. Previous studies on knowledge, attitude and practice on diabetes suggest that there is a greater need for awareness of prevention and risk factor control $[8,9]$. An insight about the knowledge and awareness of diabetes and its complications among the Anganwadi health workers can help in developing preventive strategies for the community. Therefore this study was conducted to determine and compare the level of awareness and knowledge regarding diabetes mellitus and its effect on oral health in aganwadi workers.

\section{Objectives}

1. To compare knowledge of diabetes mellitus and its effect on oral health.

2. To compare the level of awareness and its complication of diabetes mellitus in Aganwadi workers.

*Corresponding author: Dr. Grishmi Niswade, Swargiya Dadasaheb Kalmegh Smruti Dental College and Hospital, Nagpur, Maharashtra, India, Tel: +918149914078; E-mail: grish1989@gmail.com

Received October 28, 2017; Accepted November 09, 2017; Published November 15, 2017

Citation: Rathod S, Niswade G (2017) Aganwadi Community Health Workers: Awareness, Knowledge, Attitude and Beliefs about Diabetes Mellitus and Its Effect on Oral Health in Nagpur District. J Health Educ Res Dev 5: 237. doi: 10.4172/23805439.1000237

Copyright: $\odot 2017$ Rathod S, et al. This is an open-access article distributed under the terms of the Creative Commons Attribution License, which permits unrestricted use, distribution, and reproduction in any medium, provided the original author and source are credited. 
3. To explore the awareness regarding management of diabetes mellitus in Aganwadi workers.

4. To study the effect of module for awareness of diabetes mellitus in Aganwadi workers.

\section{Materials and Methods}

This study was a community based cross sectional study conducted from July 2017 to September 2017 on anganwadi workers from the areas of Hingna, Wanadongri, Gumgaon and Wadhdhamna in Nagpur district. 100 anganwadi workers and 30 interns participated in the study. In the first part, all the interns were trained for a module that contained what is diabetes, aetiology, signs and symptoms of diabetes, complications, management and prevention of diabetes mellitus in Marathi language. In second part to know the awareness of diabetes, a pre-test was conducted and a validated questionnaire was distributed to the participant. Following this the interns educated the Aganwadi workers regarding diabetes through this module for 30 minutes and also information leaflets were distributed to the participants. In third part post -test was conducted for all the participants. Therefore, participants solved the questionnaire before and after the session to compare the knowledge of participants about diabetes.

\section{Questionnaire}

An organized questionnaire was prepared based on thorough review of literature on similar questionnaires and the relationship between diabetes and oral health. The questionnaire first evaluated the demographic data such as name, age and gender following which the type of diabetes was assessed. The questionnaire also evaluated the knowledge of the participants regarding diabetes, the importance of maintaining blood sugar levels, complications of diabetes, insulin, awareness of diet and physical exercise in diabetic patients, regularity of visits to physician and oral health- diabetes association. After the aims and objective of the study were explained to the patients, they voluntarily entered in the study. Prior to data collection, informed consent was obtained from each participant. A scoring method was built by marking correct answers as "aware" and incorrect as "unaware".

\section{Statistical analysis}

The knowledge on diabetes was assessed Chi-square test. All tests were two sided with $P<0.05$ set as the significance level. All analyses were conducted using SPSS version 16 (SPSS Inc., Chicago, IL, USA).

\section{Results}

A total of 100 anganwadi workers and 30 interns participated in the study. All the anganwadi workers were females and had an education level up to grade 5. The knowledge of the participants was assessed using 16 questions related to diagnosis, risk factors, prevention and complications of diabetes and its relationship with oral health. Out of the total 100 participants, the pre-test showed an average of 36 participants to be aware about diabetes and the post test showed an average of 77 participants to have improved their knowledge. Thus, $77 \%$ of the participants were categorised as having good level of knowledge. When the pathophysiology of diabetes was concerned, 53\% were cognizant that diabetes is an ailment characterised by raised blood sugar levels (Tables 1 and 2). When asked if aware about the complications of diabetes, $42 \%$ knew that diabetes affected other organs. 32\% were aware about insulin and its uses during pre-test whereas $36 \%$ were mindful of the signs of reduced blood sugar in the body. With regards to effects of diabetes on oral health, $34 \%$ were aware that diabetes significantly affected the oral cavity as well.

Practices of the participants were assessed using questions on participant's intention to seek treatment and preventive measures such as screening for diabetes, diet and exercise. $27 \%$ of participants stated that they were aware of the significance of regular medical check-ups of diabetic patients. $47 \%$ knew about the kind of diet to be taken by diabetic patients and 25\% about the significance of regular physical activity by diabetic patients.

The knowledge and practices of the participants significantly increased after the module conducted by interns and the post test showed a suggestively better result (Figure 1).

\section{Discussion}

The present study showed that the anganwadi workers had a poor knowledge about diabetes (36\%) before the module was conducted. After the session, their knowledge increased to $77 \%$ post-test. This indicates that the expanded role of anganwadi workers in clinical setting will have a positive impact on management of diabetes. Factors affecting the knowledge of the workers can be literacy rate and social media. Similar findings were reported by another study that too revealed a shortage in the knowledge of diabetes among community members in Kenya with 27.2\% participants aware of diabetes [10]. 30.2\% of the participants were aware of diabetes on a study in Nigeria [11].

Only $34 \%$ of participants stated that they were aware of the relationship between diabetes and oral health. This shows that oral health was not a major priority for anganwadi workers. A study conducted in Saudi Arabia has shown that only 8\% of female diabetic patients visited their dentists regularly [12] and $10 \%$ patients in another study conducted in Jordan [13]. Studies from other countries have also shown that the awareness of the relationship between diabetes and oral health is lacking [14]. Thus, regular visits of diabetic patients to their dentists for proper oral health education and awareness of diabetic complications in the oral cavity is invigorated. The difference between these percentages in the present study and the latter studies could be due to the different populations investigated.

$53 \%$ of participants were aware of diabetes in the pre-test. This suggests that educational material focusing on diabetes and its complications on the general as well as oral health needs to be made available to the general population. Also, medical practitioners and dentists should be aware about the fast evolving knowledge on diabetes and its effects on oral health, so that they can educate the patients and the general population. $42 \%$ of patients were aware of the medical complications associated with diabetes and the effect of diabetes mellitus $\mathrm{n}$ body systems such as eyes, kidneys, nerves and diabetic foot. However, only $34 \%$ were aware of the oral complications of diabetes. This indicates lack of oral health counselling on the part of physicians as evidence by other studies.

It has been reported that education through paper and training packages is an organised and imperative intervention for long term raising of awareness of health issues such as oral health in different groups. In the present study, the method of training program was utilised for educating the anganwadi workers, the effect of which was satisfactory in the study. This method of education i.e., by lectures or group discussions is effective in increasing the consciousness of the participants. Other modes of education include newspapers, television and advertising [15]. However, this method of training program has the advantages of being cost effective and a significant number of individuals can be educated through them. 
Citation: Rathod S, Niswade G (2017) Aganwadi Community Health Workers: Awareness, Knowledge, Attitude and Beliefs about Diabetes Mellitus and Its Effect on Oral Health in Nagpur District. J Health Educ Res Dev 5: 237. doi: 10.4172/2380-5439.1000237

\section{Name}

Age

Type of diabetes- Type 1/type 2

Hereditary diabetes? Yes/No

Have you sought any information regarding diabetes before this?

\begin{tabular}{|c|c|c|c|}
\hline 1 & $\begin{array}{l}\text { Do you have any information regarding diabetes? } \\
\text { Do you understand what diabetes is? } \\
\text { Do you know diabetes is a lifelong disease? }\end{array}$ & Aware [ ] & Unaware [ ] \\
\hline 2 & $\begin{array}{l}\text { Do you understand the importance of maintaining blood sugar levels under control? } \\
\text { Do you know what will happen if the blood sugar levels are uncontrolled? }\end{array}$ & Aware [ ] & Unaware [ ] \\
\hline 3 & $\begin{array}{l}\text { Are you aware of the complications caused by diabetes? Yes/No } \\
\text { Are you aware that increased blood sugar levels adversely affect the heart, eyes and } \\
\text { kidneys? } \\
\text { Are you aware that diabetes affects the peripheral portion of the lower limbs which may have } \\
\text { to be amputated? } \\
\text { Are you aware that diabetes causes loss of sensation of body parts due to neuropathy? }\end{array}$ & Aware [ ] & Unaware [ ] \\
\hline 4 & Do you know why is it necessary to get your blood sugar levels checked regularly? & Aware [ ] & Unaware [ ] \\
\hline 5 & $\begin{array}{l}\text { Do you know anything about insulin? Yes/No } \\
\text { Do you believe insulin is lifesaving? } \\
\text { Do you believe insulin adversely affects the kidneys? }\end{array}$ & Aware [ ] & Unaware [ ] \\
\hline 6 & $\begin{array}{l}\text { Are you aware of the adequate blood sugar levels when fasting? } \\
\text { Are you aware of the blood sugar levels in the body at any time during the day? }\end{array}$ & Aware [ ] & Unaware [ ] \\
\hline 7 & $\begin{array}{l}\text { When blood sugar levels falls down, do you know what to do? } \\
\text { Do you understand the signs of reduced blood sugar levels in the body }\end{array}$ & Aware [ ] & Unaware [ ] \\
\hline 8 & $\begin{array}{l}\text { Do you know about your daily diet? } \\
\text { Diabetic patients cannot eat fruits. Is it wrong or right? } \\
\text { Should diabetic patients consume fiber rich vegetables or not? } \\
\text { Is it appropriate that diabetic patients can consume foodstuffs with no sugar without any } \\
\text { limit? }\end{array}$ & Aware [ ] & Unaware [ ] \\
\hline 9 & $\begin{array}{l}\text { Do you understand the importance of daily exercise in a diabetic condition? } \\
\text { Do you take special care of your legs in this diabetic condition? }\end{array}$ & Aware [ ] & Unaware [ ] \\
\hline 10 & $\begin{array}{l}\text { Are you aware of the proper techniques of taking insulin? } \\
\text { Do you know the proper site on the body where insulin injections are to be taken? } \\
\text { Are you aware when insulin should be taken? }\end{array}$ & Aware [ ] & Unaware [ ] \\
\hline 11 & $\begin{array}{l}\text { Are you aware that before or after insulin injections you should take some food? } \\
\text { Have you understood the food that you should take along with insulin? }\end{array}$ & Aware [ ] & Unaware [ ] \\
\hline 12 & $\begin{array}{l}\text { Do you know how and when to use insulin during the festival of Ramzan id? } \\
\text { Do you know how to take care of diabetes during the fasting of Ramzan? } \\
\text { Do you know it is important to take insulin during fasting }\end{array}$ & Aware [ ] & Unaware [ ] \\
\hline 13 & $\begin{array}{l}\text { Do you know the importance of insulin during pregnancy? } \\
\text { Are you aware that elevated blood sugar levels in pregnancy affects the woman and foetus } \\
\text { both? }\end{array}$ & Aware [ ] & Unaware [ ] \\
\hline 14 & $\begin{array}{l}\text { Do you know the importance of regular medical checkups and consultation in diabetes? } \\
\text { Do you know that the treatment schedule of diabetes changes according to needs? }\end{array}$ & Aware [ ] & Unaware [ ] \\
\hline 15 & Do you know that it is important to get the blood sugar levels checked daily? & Aware [ ] & Unaware [] \\
\hline 16 & Are you aware how diabetes affects the oral health and teeth? & Aware [ ] & Unaware [ ] \\
\hline
\end{tabular}

Table 1: A scoring method was built by marking correct answers as "aware" and incorrect as "unaware".

\begin{tabular}{|c|c|}
\hline Question & Pre \\
\hline 1 & 53 \\
\hline 2 & 61 \\
\hline 3 & 5 \\
\hline 4 & 3 \\
\hline 5 & 24 \\
\hline 6 & 36 \\
\hline 7 & 47 \\
\hline 8 & 49 \\
\hline 9 & 25 \\
\hline 10 & 27 \\
\hline 11 & 21 \\
\hline 12 & 24 \\
\hline 13 & 27 \\
\hline 14 & 27 \\
\hline 15 & 34 \\
\hline 16 & \\
\hline
\end{tabular}

\begin{tabular}{|c|}
\hline Pre Test \\
\hline 53 \\
\hline 61 \\
\hline 42 \\
\hline 52 \\
\hline 32 \\
\hline 24 \\
\hline 36 \\
\hline 47 \\
\hline 49 \\
\hline 25 \\
\hline 27 \\
\hline 21 \\
\hline 24 \\
\hline 27 \\
\hline 27 \\
\hline 34 \\
\hline
\end{tabular}

\begin{tabular}{|c|c|}
\hline Post Test & P value \\
\hline 89 & $<0.001$ \\
\hline 84 & $<0.001$ \\
\hline 84 & $<0.001$ \\
\hline 82 & $<0.001$ \\
\hline 77 & $<0.001$ \\
\hline 76 & $<0.001$ \\
\hline 87 & $<0.001$ \\
\hline 85 & $<0.001$ \\
\hline 88 & $<0.001$ \\
\hline 77 & $<0.001$ \\
\hline 57 & $<0.001$ \\
\hline 74 & $<0.001$ \\
\hline 82 & $<0.001$ \\
\hline 87 & $<0.001$ \\
\hline 74 & $<0.001$ \\
\hline 36 & $<0.001$ \\
\hline
\end{tabular}

Sensitivity (\%)

Specificity (\%)

\begin{tabular}{|c|c|}
\hline 55 & $50 \%$ \\
\hline 84 & 46 \\
\hline 83 & 46 \\
\hline 53 & 46 \\
\hline 81 & 68 \\
\hline 87.5 & 85.7 \\
\hline 86 & 50 \\
\hline 87 & 50 \\
\hline 72 & 44 \\
\hline 62.95 & 65 \\
\hline 62 & 74.35 \\
\hline 79.47 & 91.30 \\
\hline 88.88 & 66.66 \\
\hline 77.77 & 70 \\
\hline 23.52 & 73.91 \\
\hline
\end{tabular}

Table 2: Individual responses with $\mathrm{P}$ value. 


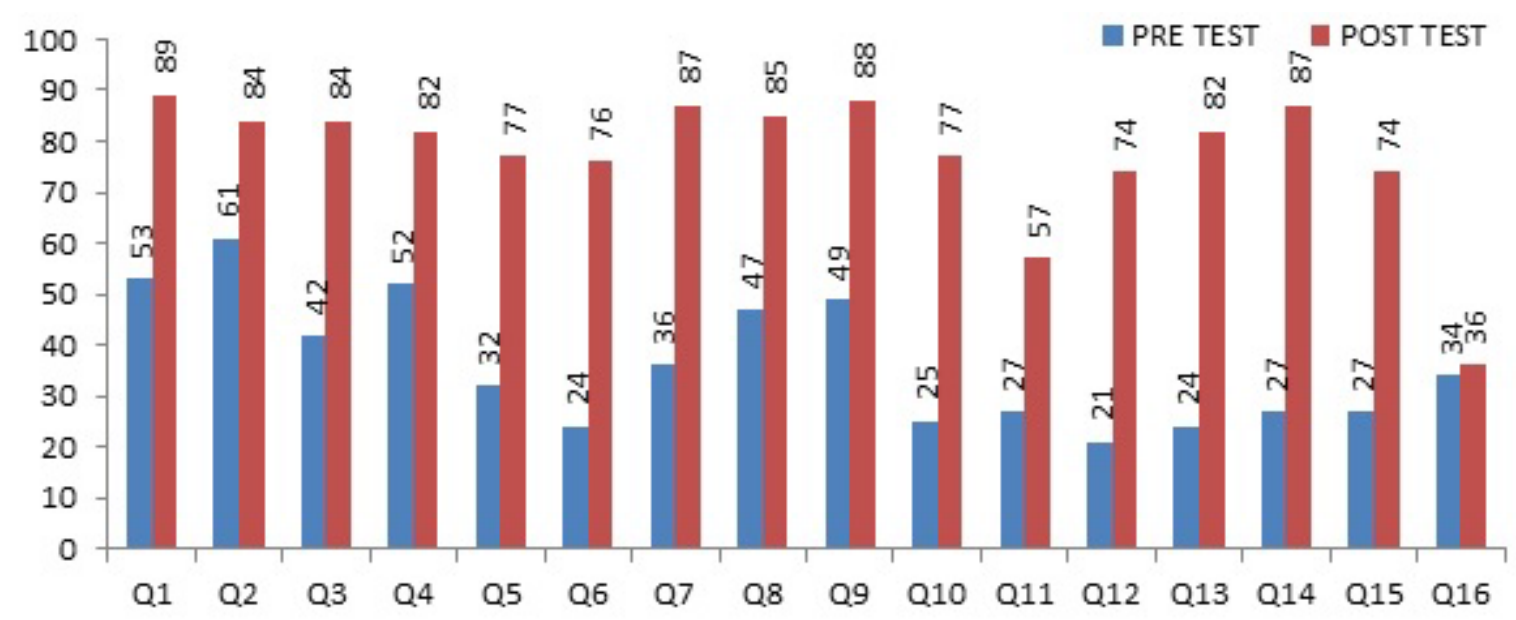

Figure 1: Graph showing the Pre-test and the post-test values among the study subjects.

\section{Limitations of the Study}

The study population consisted of anganwadi workers. Therefore the results of the study are not truly representative of the general population. All the participants were females which may create a bias. Also, the source of information was not enquired in this study. This may have helped in choosing the appropriate mode of health promotion among the population.

\section{Conclusion}

This study showed that there is a dire need of awareness and health promotion programs to be conducted for upgrading knowledge on diabetes mellitus as this matter is still neglected and needs instantaneous attention. Refining cognizance and thus altering health related behaviour and preventing complications cannot be achieved without health education. Health education attempts to modify behaviours by altering an individual's mindfulness, outlooks and beliefs about health matters.

\section{References}

1. Mealey BL, Ocampo GL (2007) Diabetes mellitus and periodontal disease. Periodontology 44: 127-153.

2. Gadsby R (2002) Epidemiology of diabetes. Adv Drug Deliv Rev 54: 1165-1172.

3. Deepa M, Bhansali A, Anjana RM, Pradeepa R, Joshi SR, et al. (2014) Knowledge and awareness of diabetes in Urban and Rural India: The Indian Council of Medical Research India Diabetes Study (Phase I): Indian Council of Medical Research India Diabetes 4. Indian J Endocrinol Metab 18: 379-385.

4. Preshaw PM, Alba AL, Herrera D, Jepsen S, Konstantinidis A, et al. (2012) Periodontitis and diabetes: A two way relationship. Diabetologia 55: 21-31.
5. The International Diabetes Federation.

6. Nathan DM, Buse JB, Davidson MB, Ferrannini E, Holman RR, et al. (2009) Medical Management of Hyperglycemia in type 2 diabetes: a consensus algorithm for the initiation and adjustment of therapy: a consensus statement of the American Diabetes Association and the European Association for the Study of diabetes. Diabetes Care 32: 193-203.

7. Shrivastava SR, Shrivastava PS, Ramasamy J (2013) Role of self-care in management of diabetes mellitus. Journal of Diabetes and Metabolic Disorders 12: 14 .

8. Islam FMA, Chakrabarti R, Dirani M, Islam MT, Ormsby G, et al. (2014) Knowledge, attitudes and practice of diabetes in rural Bangladesh: the Bangladesh population based diabetes and eye study (BPDES). PLoS ONE 9: 0110368.

9. Herath HMM, Weerasinghe NP, Dias H, Weerarathna TP (2017) Knowledge attitude and practice related to diabetes mellitus among the general public in Galle district in Southern Sri Lanka: A pilot study. BMC Public Health 17: 535.

10. Kiberenge MW, Ndegwa ZM, Njenga EW, Muchemi EW (2010) Knowledge attitude and practices related to diabetes among community members in four provinces in Kenya: a cross-sectional study. The Pan African Medical Journal 7: 2.

11. Omobuwa O, Alebiosu OC (2014) Awareness of diabetes amongst undergraduates in a Nigerian University, South West Nigeria 17: 29-33.

12. Awartin F (2009) Oral health knowledge and practices in Saudi diabetic female patients. PODJ 29: 149-152.

13. AlHabashneh R, Khader Y, Hammad MM, Almuradi MJ (2010) Diabetes Complications 24: 409-414.

14. Maha AB (2015) Periodontal health and diabetes awareness among Saudi diabetes patients. Patient Preference and Adherence 9: 225-233.

15. Taheri JB (2012) Oral health Knowledge of Diabetic Patients before and after the Education Package. AJDR 4: 47-52. 